\title{
FICÇÃO E SUBJETIVIDADE NO DOCUMENTÁRIO DE EDUARDO COUTINHO
}

\author{
Maria Sílvia Antunes Furtado \\ Universidade Estadual do Maranhão
}

\begin{abstract}
Resumo: A literatura e o cinema sempre mantiveram abertas as fronteiras que os separam, cultivando, ao longo de suas histórias, o exercício semiótico. Considerando essa perspectiva de influência mútua, este ensaio analisa a construção da narrativa fílmica no documentário de Eduardo Coutinho e levanta questões que também são pertinentes ao âmbito da teoria da literatura. Embora o documentário tenha, em sua acepção mais comum, o caráter de objetividade, o trabalho de Coutinho subverte essa perspectiva e faz emergir desse gênero a subjetividade. O cineasta é bastante sensível ao fato de que algo, diante de uma câmara, não é mais algo em si mesmo; esse algo diante de uma câmera, diante do outro já é linguagem e, portanto, é representação daquela coisa. Em Coutinho, a construção do real se mostra a partir de uma construção ficcional. Isso nos aproxima da construção narrativa literária e, também, de uma noção de sujeito da Psicanálise, cuja constituição se dá pela linguagem e na linguagem e a partir de uma estrutura de ficção.
\end{abstract}

Palavras-chave: Literatura. Cinema. Psicanálise. Eduardo Coutinho.

\section{Literatura e cinema se reinventam}

Segundo Eisenstein (2002), Griffith, nos primórdios do cinema, atribui à leitura da narrativa de Dickens, a sua "invenção" de uma nova narrativa cinematográfica que alterna as tomadas panorâmicas e os "closes". Essa dívida inaugural, no entanto, encontra, na escritura dos autores da "escola do olhar" - dentre eles, Allain Robbe-Grillet e Nathalie Sarraute - o seu avesso, pois esses autores foram influenciados em seus escritos, pelo movimento de câmera. Assim, cinema e literatura constroem interstícios no bojo de seus modus operandi para que um receba, do outro, marcas linguísticas ou formas imagéticas em seus campos distintos. De um início fecundante, a relação entre literatura e cinema insiste em manter aberta a fronteira entre esses dois campos, possibilitando, assim, o constante exercício metalingüístico. 
A história do cinema mostra que a relação entre a literatura e o cinema foi construída a partir de uma insistência em transformar a narrativa ficcional em filme. Em seus avanços, entretanto, o que era um movimento de mão única, transformou-se em diálogo entre diferentes códigos, em criação de possibilidade de trânsito entre diferentes linguagens. Avellar (2007, p. 39), ao se indagar sobre os desafios de um diretor de cinema quando se lança a transpor uma obra literária para o cinema, deixa-nos duas questões: "compor a imagem que o texto exige?

Descobrir o bocado de cinema que existe no texto" e, em seguida, afirma que a transposição entre essas duas diferentes formas de representação semiótica é uma forma de "Retratar. Não fazer parecido com.”, na medida em que não é mais necessário que o artista esteja diante de um modelo para retratá-lo. O cinema e a literatura se reinventam o tempo todo, segundo Avellar (2007, p. 433), e essa é uma forma de nos dizer "que a construção de nossas identidades passa pelo desmonte do que até então julgávamos ser: o trem de sombras que surge do nada e nos conduz até as nuvens". Essa experiência que se reedita e se tece a cada vez entre a literatura e o cinema funda uma forma discursiva que se aproxima, segundo Avellar (2007, p. 433), do ato "de esculpir a névoa".

Considerando essa perspectiva de influência mútua entre a literatura e o cinema, este ensaio analisa a construção da narrativa fílmica no cinema de Eduardo Coutinho e levanta questões que também são pertinentes ao âmbito da teoria da literatura.

\section{A fluidez dos conceitos de ficção e verdade na narrativa fílmica de Eduardo Coutinho}

Eduardo Coutinho é um dos cineastas brasileiros que mais reflete sobre as questões do cinema documentário. Seus filmes ultrapassam o registro subjetivo das representações culturais brasileiras e assumem uma construção narrativa singular, cuja ficcionalidade brota (isso pode parecer enigmático) da verdade de seus entrevistados.

Os conceitos de ficção e verdade fluidificam-se nos documentários de Eduardo Coutinho e, nessa nova perspectiva, assumem relevância. Embora o gênero documentário esteja imaginariamente associado ao real, à objetividade, à possibilidade de "mostrar ou revelar" a verdade de determinado objeto, a prevalência da subjetividade discursiva nos documentários do autor exige, no mínimo, uma reflexão sobre os limites do real e do ficcional, o que convoca, necessariamente, o conceito de verdade.

A literatura e o cinema, embora estabelecidos em planos, mídias e perspectivas diferentes, trazem pontos de contato que estabelecem o diálogo entre eles. Cada um, ao seu 
modo, estabelece uma ficção, uma narrativa. Há um ponto central em que o documentário de Coutinho alinha-se com a literatura contemporânea: não há nada mais atual, desde Kafka, do que um narrador que privilegie a subjetividade em detrimento da inteligibilidade do enredo. A literatura tem o compromisso com a verdade, mas essa verdade ficcional estabelece os seus próprios parâmetros, as suas próprias balizas, que determinam a lógica interna do romance. A ficção literária não tem compromisso com a verdade factual, mas, ao mesmo tempo, ela revela a verdade do real, confirmando a célebre frase de Picasso: "A arte é uma mentira que revela a verdade". Os documentários de Coutinho, desde o momento inaugural de "Cabra marcado para morrer", já trazem a marca da subjetividade como um traço de estilo.

Em entrevista, na época de lançamento de "Edifício Master", Coutinho confirma o interesse pelos limites tênues que separam o real do ficcional:

\begin{abstract}
Um documentarista chamado David MacDougall escreveu um livro chamado $O$ Cinema Transcultural, que é interessante. Ele diz que a partir do momento que você quer filmar o real, mesmo o etnógrafo mais puro, que não quer inventar nada, e filma 15 horas o litoral, depois 12 horas a ressaca, mesmo assim ele não pode se iludir que está filmando o real. O que ele está filmando, apenas nesse caso extremo, é o encontro entre o mundo do cineasta ou da equipe e o mundo do outro. (COUTINHO, 2002, p. 2)
\end{abstract}

Chama a atenção quando Coutinho afirma que filmar o real não é tão somente filmar o real. Esse ponto é fundamental porque, ao filmar o real, conforme a situação exemplar a que ele se refere, na qual o mar ou a ressaca se mostram para o cineasta, o que está em jogo é que o real, diante de uma câmara, torna-se linguagem e, por isso, não se trata mais do real, mas de linguagem. Entre o cineasta e seu objeto, a câmara fala e faz falar, realizando esse encontro faltoso. Quando Coutinho diz que o etnógrafo, mesmo sem querer "inventar" não está registrando o real, ele nos remete, necessariamente, a uma estrutura de ficção que é inerente a qualquer produção artística. A subjetividade do autor, a sua leitura do mundo, o seu estilo "contaminam" o objeto, construindo a sua representação. Os objetos são apreendidos somente a partir da sua representação. O famoso quadro de Renné Magritte, La Traison des images, em que sob o desenho de um cachimbo estampa-se a frase Ceci n'est pas une pipe, abre um fosso entre o objeto e sua representação.

Para a Psicanálise, o que há de mais vívido e verdadeiro em um sujeito assume a estrutura de ficção. Para Freud, a memória é o que há de mais enganoso para o sujeito. Um dos conceitos fundamentais da Psicanálise, o recalque, não pode ser dissociado do conceito de inconsciente. Digamos que a memória, à qual se atribui um valor de verdade, passa a ser frágil e inconsistente, a partir de Freud. As lembranças encobridoras são lembranças que encobrem Outra cena que não pode ser rememorada, abrindo, assim, um vazio entre a verdade da 
lembrança e o acontecido. A partir de Freud, a vivência do sujeito, as suas memórias, assumem o estatuto de ficção.

Observa-se que os documentários de Coutinho se valem das lacunas, das inconsistências ou incoerências discursivas; o cineasta as acolhe, incluindo-as, como parte integrante de um discurso. Nesse sentido a sua produção fílmica acolhe o que é de praxe se deixar à margem para que haja um privilégio do sentido. Os discursos construídos entre a consistência da língua e as suas falhas, mostram a sua fragilidade.

$\mathrm{O}$ ato falho, segundo Freud, é um ato bem sucedido, pois deixa que algo se coloque ao sujeito, que lhe seja revelada uma verdade da qual ele está apartado. Nesse sentido, Coutinho acolhe as fraturas discursivas, privilegiando a subjetividade dos entrevistados, para além da sua coerência discursiva.

Em seus documentários, Eduardo Coutinho não se interessa por discursos "prontos", tipo de queixa da vida, que é insuportável, “(...) o importante não é tanto o conceito com que ele diz e sim a forma como ele diz aquilo. É o que eu chamo de palavra incorporada. Ele constrói o discurso enquanto fala e é muito bonito" (Coutinho, 2002, p. 1).

Nesse sentido, pode-se dizer que, nos documentários de Eduardo Coutinho, a verdade subjetiva é aquela que se impõe como fio condutor da obra, a partir de uma temática. O fato de não se interessar por "discursos prontos", de não buscar respostas para teses previamente estabelecidas imprime um ritmo de trabalho à equipe do cineasta que se transforma no próprio método de trabalho, o qual se pode chamar de "a-metódico". Coutinho e sua equipe abrem uma margem bastante extensa para que os entrevistados se coloquem. As perguntas tendem a uma abertura e não a um fechamento; elas não são restritivas, não requerem uma resposta precisa, mas, ao contrário, abrem a possibilidade do entrevistado buscar em si, o que há de mais íntimo em cada um. Nesse sentido, o que aparece, nas falas, são histórias verdadeiras, de uma verdade que nem o próprio entrevistado, provavelmente, conhecia. A verdade de cada um parece nascer e morrer na própria entrevista. Eduardo Coutinho é o agente, no momento da filmagem, de uma verdade, que vem à tona como a verdade do sujeito discursivo, que se configura como uma verdade única, contraditória e que não pode ser tomada como uma tipificação.

O que é bastante interessante, em Coutinho, é que ele privilegia as contradições discursivas nas entrevistas. O cineasta mostra discursos cheios de contradições, de memórias enganosas, de sentimentos fraudados, de apego ao sofrimento, de risadas soltas, de insanidade velada, de loucura explícita, de sonhos cultivados e de reminiscências contidas. Essa forma 
documental está diretamente ligada ao real: ao cotidiano da classe média, em Edifício Master (2002); às relações de trabalho em Santa Marta, duas semanas no morro (1986); ou às questões do universo feminino como em Jogo de Cena (2007). Por outro lado, o real ganha contornos a partir da direção de Coutinho, que o revira pelo avesso. Em Edifício Master (2002), por exemplo, amor e ressentimento convivem na fala da "garota de programa" quando esta se refere à mãe, revelando seus sentimentos ambíguos por ela; a contradição revelada pelo apreço à baderna e, ao mesmo tempo, à ordem que se desenha no discurso de Maria do Céu, também “personagem” de Edifício Master.

O real que Coutinho nos mostra é cercado pela fragilidade do ser falante, pela singularidade de como cada um constrói sua própria história, uma história provisória. Cada qual se "agarra" à sua verdade e a eterniza como "a sua verdade" última. Mas, o discurso, traiçoeiro, abocanha letras e cospe verdades irreveláveis à revelia dos falantes. No ato da fala, o que se pretende verdade, por vezes, encontra o seu reverso, resvala sob as letras.

O assim chamado "acontecimento Freud" foi marcado por uma descoberta que iria instalar um hiato no pensamento moderno: "o eu não é senhor da sua casa". A concepção de um "eu" descentrado em relação ao sujeito inaugura a possibilidade de se pensar que há algo que ultrapassa a fala do sujeito. Há algo que o sujeito diz, mas há também, o que fala no sujeito para além do que ele sabe. Nesse sentido, para a Psicanálise, o que importa na condução do tratamento é que o sujeito compareça em sua divisão, para que Isso que fala no sujeito, para além do "eu”, possa se revelar como a expressão do desejo.

Para Lacan, a verdade tem estrutura de ficção, ela é não-toda; ela se apresenta sobre a forma de prosopopéia. No seminário "De um Outro ao outro", Lacan, dando voz à verdade, afirma:

Eu, a verdade, escrevi, falo - sou pura articulação, emitida para embaraço de vocês. É justamente isso que a verdade pode dizer para nos comover. Mas não é isso que grita aquele que é sofrimento, por ser essa verdade. Esse tem que saber que seu grito não passa de um grito mudo, um grito no vazio, um grito que ilustrei, no passado, com o célebre quadro de Munch. (LACAN, 2008, p. 24)

Nesse sentido, podemos afirmar, com Lacan, que o discurso do sujeito toma consistência de verdade no outro.

O filme "Santa Marta, duas semanas no morro" é, na visão de Consuelo Lins (2007), uma espécie de projeto piloto dos procedimentos de filmagem criados por Eduardo Coutinho. O espaço restrito e o tempo delimitado - já estampados no título do documentário - "vieram a servir de base para a maior parte dos filmes que Coutinho iria fazer" (Lins, 2007, p. 61). Vale ressaltar que os procedimentos adotados em "Santa Marta, duas semanas no morro" foram, 
segundo Lins, bastante intuitivos. Segundo a autora, "o objetivo principal do filme era focalizar as estratégias dos moradores para sobreviver, ou seja, os estratagemas de sobrevivência em meio a diferentes tipos de violência" (Lins, 2007, p. 62). Mas, se a temática é assim definida, o formato mostra-se ousado e inovador. Dentre os pontos abordados por Lins (2007), destacamos como peculiares, senão inovadores, os seguintes aspectos presentes em "Santa Marta" que passam a ser uma constante nos filmes de Coutinho: integrar à equipe pessoas que já tivessem uma relação anterior com a comunidade; a abolição da narração em off e a inclusão de uma trilha sonora de compositores locais. Os aspectos destacados corroboram para a construção de um filme que pode ser nomeado de "documentário da subjetividade". O contato prévio com a comunidade propicia um laço de confiança com a equipe de filmagem, predispondo os moradores locais a falar. A retirada da voz em off, por sua vez, elide o ponto de vista do narrador. Ou, seja, Coutinho privilegia a verdade que pode vir a surgir no discurso dos entrevistados. Ressalta-se, ainda, que a verdade que está em questão, para o autor, não é a verdade factual, mas a verdade subjetiva que se revela, ao mesmo tempo, para câmara e para o entrevistado. Essa verdade, na maioria das vezes é contraditória e desconhecida para ambos, não apenas para o entrevistador, como veremos adiante. A escolha da trilha sonora dos documentários também marca uma interferência do cineasta e, nesse caso, houve a minimização dessa interferência na medida em que a trilha sonora é de composição local e traduz, de forma mais subjetiva, aquela comunidade.

Observa-se que os três aspectos abordados anteriormente não renunciam à autoria, mas imprimem-lhe uma marca diferenciada. Se, por um lado, há um apagamento da interferência do cineasta tanto na filmagem quanto na montagem, há uma presença física da direção e da equipe de filmagem nas cenas. Isso, que a princípio pode parecer contraditório, nada tem ambíguo; o que se apresenta como uma contradição nada mais é do que a reafirmação de uma posição. Tanto uma como outra posição trabalham no sentido de uma construção da verdade. Não fazer constar do documentário o que é uma forma de ponto de vista do autor é preservar e privilegiar a fala dos entrevistados. Nesse sentido, por exemplo, se houvesse uma narração em off, haveria, necessariamente, a exposição de um ponto de vista sobre a comunidade e não o da comunidade. A esses elementos, Lins acrescenta outro, que corrobora com o privilégio da subjetivação nos filmes de Coutinho:

Outro elemento estético que será gradualmente excluído da montagem de Coutinho é a imagem de "cobertura", uma imagem que "cobre" - ilustrando provando, evidenciando - uma fala, uma música ou sons ambientes, um recurso central em Santa Marta. Quando um dos moradores fala em mutirão na favela, vemos uma imagem de pessoas carregando sacos de cimento; quando a professora de ginástica fala das diferenças entre o "asfalto" e a favela, vemos um plano de Botafogo; 
quando uma personagem fala da dificuldade de "segurar" os filhos em casa depois dos nove anos, vemos um plano de uma criança brincando. Essas são imagens de cobertura que servem também para disfarçar os cortes na fala dos personagens, simulando uma continuidade onde não há. (LINS, 2007, p. 64-65).

Abandonar, aos poucos, a imagem de cobertura é, também, elidir o narrador fílmico. As cenas de cobertura aparecem, como explica Lins, para imprimir uma unidade ao texto, costurar discursos. Trata-se da interferência direta do diretor, enquanto narrador imagético.

Câmaras, diretor e equipe aparecem nas cenas filmadas, registrando que essa presença terá um efeito sobre o discurso do outro, que o discurso que vemos e ouvimos foi produzido a partir de uma interferência do outro. Essa presença em cena mostra que a palavra, o discurso do sujeito ocorre porque ali se instala uma demanda para que ele fale. Os entrevistados falam porque alguém (a produção) faz uma demanda, alguém quer saber; o entrevistado tem um saber a revelar. Ele sabe e o que ele sabe tem valor para um outro. Isso o faz falar e, por vezes, como afirma Coutinho, a negociar. O sujeito tem uma história a contar. Ao reproduzir a sua história, cada um revela - e, na maioria das vezes, nem se dá conta - a dubiedade discursiva que os habita. Nesse ponto crucial reside todo o charme e beleza do documentário de Coutinho, que mostra a contradição humana. Este ponto é central porque o documental sempre se pretende pai de objetividade, aquele que busca esclarecer, elucidar, mostrar as coisas como elas são. Entretanto, é mostrando as contradições discursas que Coutinho revela sua maestria. A coerência interna do seu trabalho revela-se no limiar que ele expõe entre a verdade e a ficção; entre o sonho e o real; entre o desejo e o ato.

A dimensão temporal e espacial dos filmes de Coutinho também se coaduna ao trabalho que é sustentado pelo privilégio da subjetividade. Lins (2007, p. 66) afirma que "Coutinho só se interessa em filmar pessoas. (...) Coutinho delimita para interagir explicitamente com elas". As locações do diretor são sempre circunscritas em um espaço delimitado: Favela Santa Marta, Morro da Babilônia, Edifício Master, por exemplo. Diria que esse "só se interessa por pessoas" poderia ser desdobrado em "só se interessa pelos discursos". Se fosse um pouco além, poderia dizer que o cinema de Coutinho, sem querer parecer uma herege, é um cinema de palavras. O trabalho com o espaço restrito parece, a princípio, criar um valor de atribuição de identidade à determinada comunidade ou classe, por exemplo. Mas, longe de privilegiar a unidade, o que é mostrado é a subjetividade que ele constrói, com diferentes histórias. Esse procedimento de Coutinho distancia-se, segundo Lins (2007, p. 70) do que Jean-Claude Bernardet chama modelo sociológico de documentários que:

[...] 'transmitem uma informação que não diz respeito apenas àqueles indivíduos que vemos na tela, nem a uma quantidade muito maior deles, mas a uma classe de indivíduos e um fenômeno'. Para que isso ocorra, 'é preciso que os casos 
particulares apresentados contenham os elementos necessários para a generalização, e apenas eles'. Se, por exemplo, um personagem emigrou do Nordeste porque brigou com a mulher, e não por causa da miséria e da seca, ficará fora do filme; 'os outros terão suas motivações reduzidas a uma'. Esse processo de limpeza do real transforma o personagem em um 'tipo sociológico' - o camponês, o operário qualificado, o favelado - do qual estão excluídos os traços singulares de sua história." (LINS, 2007, p. 71).

Vemos que o exemplo a que se refere Lins em relação ao documentário clássico aproxima-se bastante da estética literária naturalista. Por outro lado, o documentário de Coutinho assume uma perspectiva que se alinha ao romance moderno.

Lins (2007, p. 67) chama a atenção, ainda, para o fato de que "Em Santa Marta, por exemplo, as marcas do passado coexistem com o presente na fala dos personagens, sem que sejam estabelecidas relações de causalidade ou sucessão entre o que está sendo mostrado". A temporalidade filmica também privilegia fragmentações discursivas em detrimento de discursos lineares. Mais uma vez, esse procedimento do cineasta conduz a tônica do filme em direção à subjetividade.

Ao afirmar que há uma impossibilidade em "separar mentira de verdade", Coutinho (2002, p.2), no entanto, delimita esse campo. A mentira separa-se claramente da verdade se ela é factual, verificável. Mas, se a mentira é subjetiva, ela é ficção e, nesse sentido, não há como separá-la da verdade:

O favelado não é igual diante do traficante, do pastor ou comigo no asfalto. Então essa coisa de teatro e real está inteiramente ligada, e o que eu quero é que eles produzam um belo retrato de si mesmos. Eu não quero, veja bem, a mitomania, isso é um outro filme que pode ser feito. $\mathrm{O}$ mitômano não me interessa, então, se o cara diz que ficou nu no Maracanã, se é mentira eu não vou botar. É um caso factual que não tem sentido, só se eu verifico antes ou depois que ele não trabalha no Banco do Brasil e que ele é solteiro, não tem filho, ele não me interessa, salvo se eu colocar na categoria de mitômano. Agora no resto... Uma pessoa me diz que viveu aqui com um alemão durante 10 anos. Foi feliz? Foi muito feliz. Poderia ter sido com um argentino durante um ano. Não interessa. (COUTINHO, 2002, p. 3).

Coutinho enfatiza bem qual a verdade que lhe interessa. Trata-se de uma verdade subjetiva que não é mensurável, que não pode ser dissociada da mentira, pois a fantasia realidade psíquica - assume um estatuto de verdade. A verdade subjetiva não é passível de julgamento. Não se relaciona aos fatos que devem ou podem ser verificados e classificados como verdadeiros ou falsos.

\section{Para concluir}

Nos filmes de Coutinho, o que não fica de fora, segundo Lins (2007, p. 72), é "uma fala indomável, que escapa a qualquer classificação e aponta em vários sentidos”. Por isso, a 
tendência de sua filmografia privilegia a contradição do sujeito, o que é dito à sua revelia e, mesmo produzindo desconfortos, mesmo mostrando-se contraditória, revela-se espontânea e verdadeira. Privilegiar o equívoco discursivo em detrimento da homogeneização que tipificaria os sujeitos imprime uma marca aos documentários de Coutinho, aquela que abraça as falhas.

No discurso, a verdade subjetiva vem entrelaçada à mentira, diria que se forja na mentira, assim como a verdade da narrativa ficcional se forja na invenção do que não existe. Ao privilegiar o discurso subjetivo, o cineasta privilegia a verdade do sujeito, uma verdade que não é verificável, que não se enquadra em uma fórmula dedutível, que nasce já com estrutura de ficção.

\section{Referências}

AVELLAR. O chão da palavra. Rio de Janeiro: Rocco, 2007.

COUTINHO, Eduardo. Entrevista com Eduardo Coutinho realizada em 25.11.2002. Revelações sobre a vida e ponto final. Entrevistadores: Daniel Wajnbert, Luciano Trigo, Marcelo Janot, Maria Sílvia Camargo. Entrevista realizada no dia 7 de novembro de 2002, no escritório da Videofilmes, Rio de Janeiro, transcrição de fita: Lyna Pereira. Disponível em: htttp://www.criticos.com.br/new/artigos/critica_interna.asp?secoes $=\& \operatorname{artigo}=176$.

EISENSTEIN, Sergei. Dickens, Griffith e nós. In: A forma do filme. Rio de Janeiro: Jorge Zahar Ed., 2002.

LACAN, Jacques. Seminário de um Outro ao outro. Trad. Vera Ribeiro. Rio de Janeiro: Jorge Zahar Ed., 2008.

LINS, Consuelo. Santa Marta, duas semanas no morro: a favela, o vídeo e o cinema possível. In: $O$ documentário de Eduardo Coutinho: televisão, cinema e vídeo. $2^{\mathrm{a}} \mathrm{ed}$. Rio de Janeiro: Jorge Zahar Ed., 2007.

\section{Referência filmográfica de Eduardo Coutinho}

CABRA marcado para morrer. Direção de Eduardo Coutinho. Produção de Eduardo Coutinho Produções Cinematográficas e Produções Cinematográficas Mapa. Rio de Janeiro: Globo Video, Gaumont do Brasil, 1964/84. 35mm (119min), sonoro, PB e color. Port. Sem legenda.

EDIFÍCIO master. Direção de Eduardo Coutinho. Produção de Maurício Andrade Ramos e João Moreira Salles. Rio de Janeiro: Videofilmes, 2002. Vídeo VHS Rip (110min). Sonoro, color. Port. Sem legenda.

SANTA marta, duas semanas no morro. Direção de Eduardo Coutinho. Rio de Janeiro: Iser Vídeo, 1987. Vídeo VHS Rip (54min). Sonoro, color. Port. Sem legenda. 
JOGO de cena. Direção de Eduardo Coutinho. Produção Raquel Freire Zangrandi e Bia Almeida.Rio de Janeiro: Videofilmes, 2007. Vídeo VHS Rip (105min). Sonoro, color. Port. Sem legenda.

[Recebido em março de 2012 e aceito para publicação em junho de 2012]

\section{Fiction and subjectivity in the documentary by Eduardo Coutinho}

Abstract: Literature and cinema have always kept open boundaries that separate them, cultivating, throughout their histories, the semiotic exercise. Considering this perspective of mutual influence, this essay examines the construction of filmic narrative in the documentary by Eduardo Coutinho and raises questions that are also relevant to the scope of the theory of literature. Although the documentary has, in its most common sense, the character of objectivity, the work of Coutinho subverts this perspective and brings out the subjectivity. The filmmaker is very sensitive to the fact that something in front of a camera is no longer something in itself anymore. When something is before a camera, before another one, it is language; it is a representation of something. In Coutinho, the construction of the reality is shown as a fictional construction. This brings us closer to the literary narrative construction, and also to the conception of the subject in Psychoanalysis, whose constitution is given by the language and in the language as a structure of fiction.

Keywords: Literature. Cinema. Psychoanalysis. Eduardo Coutinho.

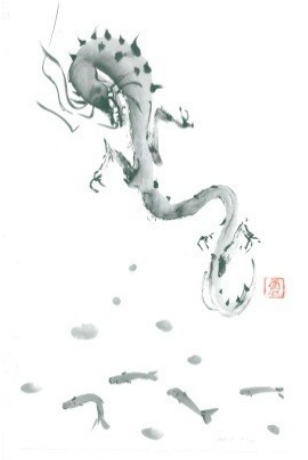

